\title{
Maintaining global coherence in reading: The role of sentence boundaries
}

\author{
ALEXANDRLA E. GUZMÁN and CELIA M. KLIN \\ State University of New York, Binghamton, New York
}

\begin{abstract}
In four experiments, we examined the reinstatement of backgrounded information in locally coherent passages, investigating the influence of syntactic boundaries, such as periods, on the time course of this process. In Experiment 1, using a line-by-line reading paradigm, readers were delayed in noticing a contradiction on a target line when the sentence continued onto a posttarget line. Consistent with this, in Experiments $2 \mathrm{~A}$ and $2 \mathrm{~B}$, the results of a recognition probe demonstrated that relevant concepts from long-term memory were not integrated immediately unless the contradiction was followed by a period. Experiment 3 demonstrated that sentence boundaries are sufficient to facilitate the integration of related background information but are not necessary; additional time served the same purpose. Consistent with a memory-based text-processing framework, it appears that the reactivation of related information is initiated automatically but that an integration stage is influenced by such factors as syntactic boundaries.
\end{abstract}

An important goal of studies of reading comprehension is to specify the cognitive processes involved in building a representation of the text. One component of this involves investigating how readers integrate currently read information with information from earlier in the text. Although it is clear that readers often reactivate earlier portions of the text from memory when the coherence of the story breaks down (e.g., Klin, 1995; O'Brien, Duffy, \& Myers, 1986), recent studies have suggested that readers may also reactivate backgrounded information when the story is locally coherent - that is, when the currently read sentence follows easily from the prior two or three sentences (Albrecht \& Myers, 1998; O'Brien, Rizzella, Albrecht, \& Halleran, 1998). For example, in a recent study, Albrecht and Myers demonstrated that readers accessed backgrounded goal information (e.g., Wanda needed to make an airline reservation. ... She sat down in her leather chair and looked through the telephone book), if the goal was not satisfied (i.e., Wanda had not made the reservation) and the current text reinstated some part of the goal context (e.g., Wanda sat down in her leather chair). Similarly, in another series of studies (Albrecht \& O'Brien,

\footnotetext{
Experiments 1,2A, and 2B were conducted in partial fulfillment of the requirements for A.E.G.'s MA degree, submitted to the State University of New York at Binghamton and conducted under the direction of C.M.K. We thank the members of A.E.G.'s thesis committee, Cynthia Connine and Albrecht Inhoff, for providing helpful recommendations regarding this project. We are also grateful to William $\mathrm{H}$. Levine and Jerome L. Myers for comments on an earlier version of this manuscript, to Rachel Altschuler, Lia Kieren-Dexter, and Dawn Melzer for their assistance in preparing experimental materials and with data collection, and to Jerome L. Myers, Edward J. O'Brien, and Anne E. Cook for sharing stimulus materials. Correspondence concerning this article should be addressed to A. E. Guzmán or C. M. Klin, Department of Psychology, State University of New York, Binghamton, NY 13902-6000 (email: br00542@binghamton.edu or cklin@ binghamton.edu).
}

1993; Myers, O'Brien, Albrecht, \& Mason, 1994), readers had difficulty processing a target sentence (e.g., Mary ordered a hamburger) that contradicted earlier, backgrounded information (e.g., Mary was a vegetarian), even though the target line followed naturally from the preceding few lines.

In the present experiments, we investigated the influence of sentence boundaries on the time course of reinstating backgrounded information in the absence of a break in coherence. Before describing these experiments, we will consider the theoretical framework that has been put forth to account for the previous findings. According to a bottom-up, or memory-based, view of text processing (McKoon, Gerrig, \& Greene, 1996), such as Kintsch's (1988) construction-integration model or Myers and O'Brien's (1998) resonance view, the clause or proposition currently being processed acts like any other input to memory. In the construction or resonance stage, the text information in working memory acts as a retrieval cue and automatically activates related information in long-term memory. In the contradiction experiments, when readers encountered the target line Mary ordered a hamburger, features of this input, such as eats meat and likes greasy food, acted as retrieval cues and made contact with related traces in memory, such as doesn't eat meat, and is a health nut. In a second stage, elements whose activation exceeds a threshold enter an integration phase, in which activation is spread throughout the network. When the integration stage is complete, a subset of the activated elements from the construction stage will have reentered, or been reinstated in, working memory. In the contradiction experiments, the reinstated traces were incompatible with the current input, resulting in elevated reading times.

An important element of the construction stage is that it is continuous and fast, with each new input acting as a signal to memory (see, e.g., Klin, 1995; Klin \& Myers, 
1993). Whereas there is evidence supporting the idea of the continuous, automatic nature of the construction stage (e.g., O'Brien, Raney, Albrecht, \& Rayner, 1997), less is known about the time course of the integration stage and the factors that influence it. The results of the goal experiments (Albrecht \& Myers, 1998) and the contradiction studies (Albrecht \& O'Brien, 1993; Myers et al., 1994; O'Brien et al., 1998) suggest that the integration process may be completed quickly, at least under some conditions. In those experiments, the contradictory information appeared at the end of a target line, and a slowdown in reading occurred on the target line. However, although the slowdown seems to have occurred as soon as the contradictory information was encountered, this may not be a general phenomenon. In both of these sets of experiments, the target line was a full sentence, ending with a period (e.g., Mary ordered a hamburger.). If the target line had not ended with a period, the slowdown might have been delayed. Sentence endings may play a specialized role, acting as a signal for readers to complete the integrative processes before moving on to the next sentence. Or there may be a natural pause that occurs when readers reach the end of a sentence. In other words, sentence endings may not play a specialized role, invoking strategic processes, but may simply provide the extra time that is needed for the integration process to be completed.

Although the influence of sentence endings on the reinstatement of backgrounded information has not been tested, evidence does exist that at least some integrative processes occur at the ends of sentences. Using eye movements as the dependent measure, Just and Carpenter (1977) found that when readers drew an inference connecting a critical word in the current sentence (e.g., killer) with a word in the previous sentence (e.g., murdered), a slowdown occurred both on the critical word and at the end of the sentence. Furthermore, even when there was no inference to be drawn, readers spent additional time on sentence final words than on words in the middle of a sentence (Just \& Carpenter, 1980). Similarly, Rayner, Sereno, Morris, Schmauder, and Clifton (1989) found that gaze durations were $53 \mathrm{msec}$ longer when a target word was at the end of the sentence than when it was at the end of a clause. Thus, a number of processes may occur during sentence wrap-up, including an attempt to "handle any inconsistencies that could not be resolved within the sentence" (Just \& Carpenter, 1980, p. 345).

The goal of the present set of experiments was to explore the effect of a syntactic boundary on the time course of reinstating backgrounded information in the absence of a coherence break. Although there has been considerable research examining the time course of reactivating referents of anaphors under various text conditions (e.g., Dell, McKoon, \& Ratcliff, 1983; Duffy \& Rayner, 1990; Garnham, Oakhill, \& Cain, 1997; McDonald \& MacWhinney, 1995; Oakhill, Garnham, \& Vonk, 1989), these findings may not generalize to global, elaborative inferences. Assuming that the primary goal of readers is to make sense of the current input, processes that are necessary for co- herence, such as connecting an anaphor with its referent, may take precedence. With elaborative inferences, the integration process may be more likely to be affected by the status of various text factors, such as sentence boundaries.

Four experiments were conducted to investigate the processes involved in integrating information from longterm memory when texts are locally coherent and the influence of sentence boundaries on those processes. In Experiment 1 , passages were presented that were similar to those used in the previous contradiction experiments (Albrecht \& O'Brien, 1993; Cook, Halleran, \& O'Brien, 1998; Myers et al., 1994; O'Brien et al., 1998), but the period was removed from the contradiction line. If the reinstatement process takes more time in the absence of a sentence boundary, the contradiction effect should be eliminated on the target line. In Experiments 2A and 2B, a recognition probe, which was the key concept in the relevant backgrounded material (e.g., vegetarian), was presented at the end of the target line to determine whether the critical backgrounded character traits were reinstated immediately. Finally, in Experiment 3, we asked at what point the contradiction is noted in the absence of a sentence boundary and whether sentence endings are necessary or merely sufficient for the reactivation of backgrounded information.

\section{EXPERIMENT 1}

In Experiment 1, we began to explore the influence of sentence boundaries on the integration of backgrounded information. Materials were used that were similar to those from previous contradiction studies (Albrecht \& O'Brien, 1993; Cook et al., 1998; Myers et al., 1994; O'Brien et al., 1998), except that there was no period on the target line: The target sentence continued onto a posttarget line. A sample passage can be found in Appendix A. As in the previous experiments, there were two versions of each passage-a consistent version, in which characters' physical or motivational characteristics (e.g., Mary loved junk food) were described in a way that was consistent with the action in the subsequent target line (e.g., Mary ordered a cheeseburger and fries), and an inconsistent version, in which characters' physical or motivational characteristics (e.g., Mary was a vegetarian) were described in a way that was inconsistent with the action in the target line. A neutral posttarget line that ended with a period followed the target line (e.g., and handed the menu over to Ruth.). Reading times on the target and posttarget line were the dependent measures.

If the pattern of results replicates the findings from the previous contradiction studies (Albrecht \& O'Brien, 1993; Myers et al., 1994; O'Brien et al., 1998), with a slowdown on the target line in the inconsistent condition, this would suggest that the integration process is independent of syntactic boundaries. Despite the attentional demands involved in sentence-level processing, readers have sufficient resources available to simultaneously integrate information from long-term memory that has been substantially backgrounded and is not needed for local coherence. 
On the other hand, if the slowdown is delayed to the posttarget line, this would demonstrate that readers sometimes move on before they have completed all of the relevant global, elaborative processing. This result would suggest that although the reactivation of related information in long-term memory probably begins immediately, time is needed for those traces to be integrated with the current input, at least under some conditions. In addition, this would demonstrate that sentence boundaries are influential.

\section{Method}

Participants. Thirty members of the State University of New York at Binghamton community participated in exchange for $\$ 5$ or course credit.

Materials. Fourteen experimental passages were used, with two versions of each. ${ }^{1}$ A sample passage can be found in Appendix A. Each passage can be viewed as consisting of five sections: an introduction, the critical elaboration, backgrounding, the target line, and the posttarget line. The introduction averaged 5 lines and was followed by the critical consistent/inconsistent elaboration, averaging 4 lines. This elaboration described some physical or motivational characteristic of the protagonist. In the consistent version, this information was consistent with the action subsequently described in the target line. In contrast, in the inconsistent version, this information was inconsistent with the action in the target line. This was the only section of the passage that differed across the two versions. The third section consisted of approximately 12 lines of backgrounding, which was neutral with respect to the critical character trait. This was followed by the target line, which did not end in a period, and by a posttarget sentence that completed the critical sentence, ending in a period. The posttarget line was neutral with respect to the critical characteristic. The experimental passages ranged from 20 to 31 lines. There were also 17 filler passages, which were similar to the experimental passages but did not contain contradictory information. Thus, for each participant, only 7 out of 31 passages contained contradictory information. In addition, approximately $70 \%$ of the lines, in both the experimental and the filler passages, did not end with a period.

Design. Experimental passages were randomly assigned with two constraints: (1) Each participant saw half of the passages in each version, and (2) across participants, each passage appeared equally often in each version. The order of presentation was the same for all the participants.

Procedure. The participants were tested individually in sessions that lasted approximately $45 \mathrm{~min}$. They were instructed to read each passage for comprehension at their own pace. The passages were presented one line at a time on a computer monitor. Each trial began with the presentation of the word "Ready" at the center of the screen The participants controlled the presentation of the text with a line advance key. Each keypress caused the current line to be erased and the next line to be presented. After the last line of the passage, the string ??? was presented for $750 \mathrm{msec}$ and was followed by a yes/no comprehension question. The participants responded by pressing corresponding yes/no keys on a response box. On trials on which the participants responded incorrectly, the word "Error" appeared in the center of the screen for $1,500 \mathrm{msec}$. Halfway through the experiment, the participants were given a break. To familiarize the participants with the procedure, they completed three practice passages before beginning the experiment.

\section{Results and Discussion}

In all the experiments, $t_{1}$ refers to tests in which the error term is based on subject variability, and $t_{2}$ refers to tests in which the error term is based on item variability. In all the analyses, an alpha level of .05 was used. For the present experiment, the mean reading times for the target and the posttarget lines were computed after discarding outliers, as defined by Tukey's (1977) criterion ${ }^{2}$; this eliminated $6.7 \%$ of the data.

Despite the fact that the target line contained a very clear contradiction, readers did not slow down until the posttarget line. Although target line reading times in the inconsistent condition were longer than those in the consistent condition ( 1,868 vs. $1,813 \mathrm{msec}$, respectively), this $55-\mathrm{msec}$ reading time difference did not approach significance $\left[t_{1}(28)=1.24, S E M=44.15, p=.23 ; t_{2}(13)=0.44, S E M=\right.$ $74.65, p=.67]$. In contrast, reading times on the posttarget line were $216 \mathrm{msec}$ longer in the inconsistent version than in the consistent version $\left[1,938\right.$ vs. $1,722 \mathrm{msec} ; t_{1}(28)=$ $3.39, S E M=63.46, p=.002 ; t_{2}(13)=2.56, S E M=81.91$, $p=.024]$.

Despite the fact that these passages were very similar to those used in a number of previous studies (e.g., Albrecht \& O'Brien, 1993; Cook et al., 1998; Myers et al., 1994; O'Brien et al., 1998), the contradiction effect was not found on the target line. This is impressive, given that the contradiction effect appears to be quite robust, having been found under a wide range of conditions. For example, Myers et al. found a slowdown on the target, contradiction line even when a description of a secondary character (e.g., Mary's friend) intervened between the critical information and the target line, presumably shifting the focus from Mary and her traits. O'Brien et al. (1998) found a slowdown on the target line even when the original description was strongly qualified (e.g., Mary used to be a vegetarian), essentially eliminating the contradiction. And finally, Guzmán (1998) found a slowdown on the contradiction line even when the topic had been shifted to a more salient theme. In contrast, in this experiment, simply removing the period from the target line was sufficient to delay this robust effect.

\section{EXPERIMENTS 2A AND 2B}

In Experiments 2A and 2B, we considered two explanations for the delayed effect in Experiment 1 . According to the first, this was due to a delay in integrating the related traces from long-term memory. Given a memorybased model, relevant concepts in long-term memory, such as vegetarian, should have been activated as soon as the target line was read. However, those reactivated concepts may not have been fully integrated by the time readers hit the key to bring on the posttarget line. Given the attentional demands involved in sentence-level processing, there might not have been sufficient resources left to complete the elaborative, global inference before the eyes moved on to the next line. This is in contrast with previous contradiction experiments, in which the target line ended with a period and the contradiction was noted on the target line. However, sentence endings may free attentional resources or provide additional time needed to complete these global, text-level processes. 
In contrast, readers may have immediately reinstated the contradictory information from earlier in the passage and noticed the discrepancy. However, the slowdown may have been delayed owing to an expectation that the remainder of the sentence would serve to repair the contradiction. For example, the target sentence might have read: Mary ordered a cheeseburger and fries ... because she'd had a craving for weeks. It would be reasonable for readers to expect the contradiction to be repaired on the posttarget line, given that stories usually make sense. That is, vegetarians do not usually eat meat, someone suffering from acrophobia does not go skydiving, a deaf person cannot hear a plea for help; if they do, an explanation is warranted and will usually be found soon afterward.

The participants read passages similar to those in Experiment 1. A sample passage can be found in Appendix B. However, in contrast to Experiment 1 , a recognition probe was presented immediately after the target line. The recognition probe was the key concept from the critical information section (e.g., vegetarian), representing the protagonist's critical motivational or physical characteristic. In addition, whereas the inconsistent and consistent versions of the passages in Experiment 1 differed in the critical information section (e.g., Mary liked/hated junk food), and had the same target line, in Experiments $2 \mathrm{~A}$ and $2 \mathrm{~B}$, the two versions of the passage had the same critical information section (e.g., Mary was a vegetarian) but different target lines. The contradiction version had the same target line as the inconsistent passages from Experiment 1 (e.g., Mary ordered a cheeseburger and fries), whereas in a neutral version, the target line was neutral with respect to the elaboration section (e.g., Mary ordered an iced cappuccino). This was done so that the correct response to the recognition probe (e.g., vegetarian) was yes in both versions.

The goal of Experiment 2A was to examine the sensitivity of the recognition probe task. Because the target lines ended with a period, there should be facilitation to the probe in the contradiction condition. Based on the findings of previous contradiction studies (Albrecht \& O'Brien, 1993; Cook et al., 1998; Myers et al., 1994 ), after reading Mary ordered a cheeseburger and fries in the contradiction condition, the concept vegetarian should be fully reinstated. In addition, the target reading time data are of interest. Although reading times are being compared on different last lines, these lines were equated for length and syntactic structure. The data should therefore provide a replication of the previous contradiction studies, with longer reading times in the contradiction condition, as well as a contrast for the null effect in Experiment 1.

In contrast to Experiment 2A, in Experiment 2B the target line did not end in a period. Therefore, if the delayed contradiction effect in Experiment 1 was the result of a delay in the completion of the reinstatement process, there should be a reduction or elimination of facilitation of the recognition probe. The critical concept (e.g., vegetarian) will not have been fully integrated with the current text, and readers' attentional resources will be diverted from the probe task to the integration process. Conversely, if readers noticed the contradiction as soon as they read Mary ordered a cheeseburger and fries but were waiting to determine whether the posttarget line resolved the inconsistency, responses to the probe word should be facilitated in the contradiction condition. In addition, given either hypothesis, the target line reading time data should provide a replication of Experiment 1 : Reading times should be equal on the target line across the two versions.

\section{Method}

Participants. In Experiment 2A, 48 undergraduates from the State University of New York at Binghamton participated in exchange for course credit. In Experiment 2B, 35 members of the State University of New York at Binghamton community participated in exchange for $\$ 5$ or course credit. One participant made more than $25 \%$ probe errors; these data were discarded. Therefore, data analyses were based on 34 participants.

Materials. The 14 experimental passages from Experiment 1 were modified so that there were four versions of each passage: period/contradiction and period/neutral in Experiment $2 \mathrm{~A}$ and noperiod/contradiction and no-period/neutral in Experiment 2B. A sample passage can be found in Appendix B. The critical information from the inconsistent version of Experiment 1 was used in all four versions (e.g., Mary is a vegetarian) and the target line from the inconsistent version of Experiment 1 (e.g., Mary ordered a cheeseburger and fries) was used in the contradiction versions. However, in the neutral version, the action in the target line (e.g., Mary ordered an iced cappuccino) was neutral with respect to the critical physical or motivational characteristic of the protagonist. Across cunditions, the target line was equated for length and syntactic structure. In Experiment $2 \mathrm{~A}$, the target line ended with a period, and in Experiment 2B, it did not. Finally, each passage was followed by a probe word that represented the protagonist's critical physical or motivational characteristic. Note that yes was the correct response to the recognition probe in both conditions. There were 24 filler passages, providing a total of 20 yes responses and 18 no responses for the recognition probes in each sub-experiment.

Design. The design was the same as that in Experiment 1.

Procedure. The procedure was the same as that in Experiment 1, except that a probe word was presented at the end of each passage. After the final line of the passage had been presented, the string XXX was presented for $500 \mathrm{msec}$ when the participants pressed the advance key. This was immediately followed by a probe word, all in capital letters, centered on the screen. The participants were required to indicate whether the probe had been in the preceding text by pressing a yes or a no key on a response box, as quickly and accurately as possible. After responding, the participants received feedback regarding their response time. On trials in which the participants took longer than $1,500 \mathrm{msec}$, they were told to respond more quickly. Immediately after responding to the probe, the string ??? was presented for $750 \mathrm{msec}$, followed by a comprehension question.

\section{Results and Discussion}

Experiment 2A: Period condition. Reading times for the target line were 120 msec longer in the contradiction condition than in the neutral condition $(1,834$ vs. $1,714 \mathrm{msec}$, respectively). This difference was reliable $\left[t_{1}(47)=3.58, S E M=33.71, p=.001 ; t_{2}(13)=2.50\right.$, $S E M=54.27, p=.027]$. The longer reading times in the contradiction condition provide a replication of previous 
findings (Albrecht \& O’Brien, 1993; Myers et al., 1994), as well as a useful contrast for the null finding in Experiment 1: When the target line ended in a period, readers slowed down in the inconsistent condition.

More central to the hypotheses are the recognition data. The mean correct probe response times were computed after discarding outliers (Tukey, 1977). This eliminated $5.5 \%$ of the data. In addition, error rates were $13 \%$ and $15 \%$ in the contradiction and the neutral conditions, respectively. These relatively high error rates are not surprising, given that there were approximately 100 words intervening between the last mention of the key concept and the presentation of the probe. Importantly, error rates did not differ across conditions $(p>.5)$.

Consistent with the finding of longer reading times in the contradiction condition, recognition latencies were $40 \mathrm{msec}$ shorter following the target line in the contradiction condition than following the target line in the neutral condition [ 842 vs. $882 \mathrm{msec}$, respectively; $t_{1}(47)=3.14$, $S E M=12.83, p=.003 ; t_{2}(13)=3.33, S E M=15.67, p=$ $.005]$. The probe task is clearly sensitive to the reactivation from long-term memory of the protagonist's critical traits. When the target line ended in a period, readers reinstated related information from long-term memory, leading to faster reaction times on the recognition probe and slower reading times. Furthermore, the finding is impressive, given the conservative nature of the test: The participants responded more quickly to the recognition probes in the contradiction condition, despite the fact that reading times on the target line were significantly longer. That is, despite the 120-msec slowdown in reading, significant facilitation was found to the probe in the contradiction condition. The true effect size for the probe task may be even larger, assuming there was some spillover from the reading task.

Experiment 2B: No-period condition. In contrast to Experiment 2A, reading times for the target line were almost identical for the contradiction and the neutral conditions $\left[1,882\right.$ vs. $1,862 \mathrm{msec}$, respectively ${ }^{3} ; t_{1}(33)=0.453$, $S E M=43.73, p=.65 ; t_{2}(13)=0.23, S E M=91.14, p=$ .82]. Again, given that reading times are being compared on different last lines, this result must be viewed with some caution. However, this provides a useful contrast for Experiment 2A, as well as a replication of Experiment 1. When there was no period at the end of the target line, there was no slowdown on the target line in the inconsistent condition.

Mean correct probe response times were computed after discarding outliers (Tukey, 1977); this eliminated $5.0 \%$ of the data. Probe error rates were similar to those in Experiment $2 \mathrm{~A}-15 \%$ and $13 \%$ in the contradiction and the neutral conditions, respectively. Again, these did not differ across conditions ( $p>.5$ ). In contrast to Experiment $2 \mathrm{~A}$, however, probe response times were no faster in the contradiction condition than in the neutral condition. In fact, they were nonsignificantly slower $[1,017$ vs.
$1,001 \mathrm{msec} ; t_{1}(33)=1.030, S E M=15.01, p=.31 ; t_{2}(13)=$ $0.17, S E M=22.23, p=.87]$.

Most important, on the basis of the combined results from Experiments $2 \mathrm{~A}$ and $2 \mathrm{~B}$, we can conclude that the relevant concepts in long-term memory were not fully reinstated at the earliest possible point after readers encountered the contradictory information in the target line. This finding does not support the hypothesis that readers immediately noticed the inconsistency but expected the remainder of the sentence to repair it. Given both the probe and the reading time data, there was no evidence of integration of the critical backgrounded information after readers completed the target line that lacked a period. Although activation should have begun to accrue immediately, the integration process was not complete. In addition to potentially reducing the activation of the concept, the attentional resources involved in the integration process should have diverted resources from the probe task, slowing responses. Finally, given the different pattern of results in Experiments $2 \mathrm{~A}$ and $2 \mathrm{~B}$, it is evident that syntactic boundaries play an influential role in the reinstatement process. In Experiment 3, we attempted to further elucidate the nature of that role.

\section{EXPERIMENT 3}

In Experiments 1 and 2B, there was no immediate slowdown on a contradictory target line when it did not end with a period. Furthermore, a probe word representing the critical character trait in long-term memory was not facilitated. However, based on the previous contradiction experiments and on Experiment $2 \mathrm{~A}$, it seems that if readers encounter a sentence boundary before the reinstatement process is complete, it will be completed at that time. Assuming that text inputs act like any other input to memory, sentence boundaries should be sufficient, but not necessary, for the reactivation process to proceed. That is, the integration of backgrounded concepts should not be initiated by the sentence ending; sentence endings should simply free attentional resources, allowing the process to be completed at an earlier point. But even without encountering the end of the sentence, readers should eventually notice the contradiction.

A contrasting account is that some of the intersentence processing that takes place while reading a narrative is routinely delayed until the end of the sentence. In this way, sentence endings are necessary, rather than simply sufficient, acting as a cue for the integration process to begin. Although readers complete anaphoric inferences, for example, before they reach the end of the sentence, perhaps when the text is locally coherent the reinstatement of information from long-term memory is delayed until readers encounter a syntactic boundary. Given this account, in Experiment 1 readers only became aware of the contradiction at the end of the posttarget line-that is, when they reached the end of the sentence. 
To determine exactly what role sentence endings play, in this experiment, the inconsistent and consistent versions of the passages from Experiment 1 were used with one modification. Although the target line still did not end in a period, several words were added after the critical, contradictory information. A sample passage can be found in Appendix $\mathrm{C}$. In this passage, the target line was she ordered a cheeseburger and fries and handed the menu. If sentence endings play a critical role, with readers waiting for this cue to complete the integration process, the contradiction effect should still be absent on the target line, replicating the results of Experiments 1 and 2B. On the other hand, if sentence endings are merely sufficient, rather than necessary, adding several words after the critical, contradictory information should provide the time needed for the reinstatement process to be completed. If this is the case, the contradiction effect should be found on the target line.

\section{Method}

Participants. Thirty-two undergraduates at the State University of New York at Binghamton participated in exchange for course credit.

Materials. The 14 experimental passages from Experiment 1 were modified so that several words were added to the target line. Instead of the target line ending with the critical, contradictory information, several words were added that were neutral with respect to the critical physical or motivational traits and tended to add very little new information. Across passages, three to five words were added to the target line. Also, the 17 filler passages from Experiment 1 were interspersed in between the experimental passages.

Design and Procedure. The design and procedure were identical to those in Experiment 1.

\section{Results and Discussion}

The mean reading times for the target and posttarget lines were computed after discarding outliers (Tukey, 1977); this eliminated $2 \%$ of the data. In contrast to Experiments 1 and $2 \mathrm{~B}$ (the no-period condition), reading times on the target line were longer in the inconsistent condition than in the consistent condition $(2,301$ vs. $2,047 \mathrm{msec}$, respectively). This $254-\mathrm{msec}$ difference was reliable by subjects $\left[t_{1}(31)=3.98, S E M=63.89, p<.001\right]$ and approached significance by items $\left[t_{2}(13)=1.91\right.$, $S E M=129.84, p=.08]$. Despite the fact that the target line did not end in a period, the readers were clearly aware of the contradiction, reactivating related concepts from long-term memory. Reading times on the posttarget line were also slower in the inconsistent condition than in the consistent condition ( 1,519 vs. $1,400 \mathrm{msec}$, respectively). This was reliable by subjects $\left[t_{1}(31)=2.50, S E M=47.80\right.$, $p=.018]$ and approached significance by items $\left[t_{2}(13)=\right.$ $1.90, S E M=58.81, p=.08]$.

These findings provide no support for the hypothesis that sentence endings are necessary for the integration of backgrounded information. In this experiment, despite the fact that the target line was locally coherent and did not contain a sentence boundary, readers reinstated related concepts from long-term memory. Thus, although syntactic boundaries, such as sentence endings, seem to facilitate the comprehension process, the integration process proceeds even if there is no syntactic boundary.

\section{GENERAL DISCUSSION}

Several recent studies (Albrecht \& Myers, 1998; Albrecht \& O'Brien, 1993; Myers et al., 1994; O'Brien et al., 1998) have demonstrated that there are a number of conditions under which readers reactivate backgrounded information even when a text is locally coherent. These findings contribute to our understanding of the processes involved in building a globally coherent representation of a narrative and are consistent with a memory-based textprocessing framework. Passages were locally coherent when the inconsistency occurred, giving readers no reason to initiate a search of memory. Unless we assume that readers actively review the entire story with each new input, it appears that text inputs automatically cause related information in memory to become reactivated, regardless of the coherence of the text.

Despite evidence that the construction (Kintsch, 1988), or resonance (Myers \& O’Brien, 1998), process proceeds continuously and automatically, there is little known about the time course of the integration process and the factors that affect it. In previous studies using the contradiction paradigm (Albrecht \& O'Brien, 1993; Myers et al., 1994), the integration process appears to have been completed quickly, before readers moved on to the next word. However, the contradictory information always appeared just before the end of the sentence. Thus, although the slowdown seemed to occur as soon as the contradictory information was encountered, the reinstatement process may have been completed during sentence wrap-up. In other words, the immediacy of the slowdown may not be a general phenomenon. The goals of the experiments presented here were to explore the time course of reinstating backgrounded information in the absence of a break in coherence and to determine whether sentence boundaries influence that process.

In Experiment 1, there was no evidence that readers noticed the contradiction immediately, on the target line, when the sentence containing the contradiction continued onto a posttarget line. This delay in the contradiction effect occurred despite the fact that characters were described as acting in ways that strongly and directly contradicted an earlier description (e.g., a vegetarian ordering a hamburger, someone with a fear of heights going skydiving, a deaf man hearing a scream). Experiment $2 B$ provided converging support for the conclusion that the related information was not reinstated at the earliest possible point: When the target line in the contradiction condition did not end in a period, there was no facilitation on a recognition probe representing the critical character trait.

After finding that the integration process was completed immediately only when the contradictory information appeared at the end of the sentence, in Experiment 3 we asked whether the presence of a sentence ending was 
necessary for the process to be completed. That is, as long as a currently processed sentence fits with the prior sentence or two, is it the case that readers do not reinstate related information in long-term memory until they reach the end of the sentence? Or does the sentence ending simply speed up the integration process? That is, is the period merely sufficient? The results of Experiment 3 provided support for the latter position. When several words were added after the contradictory information, a slowdown occurred on the target line in the inconsistent condition, despite the absence of a sentence ending.

There are several possible roles that sentence endings may play in discourse comprehension. First, when readers encounter a period, the natural pause that occurs may provide the time needed to complete the integrative process. In this way, sentence endings may act much like the additional words on the target line of Experiment 3, providing the extra time needed for activation to accrue on the backgrounded information and for that information to be integrated with the target line. In addition, attentional resources may be freed that allow for the completion of elaborative, global inferences. In contrast, the sentence ending may play a somewhat more specialized role: Perhaps readers do not move on to the next sentence until all integrative processes are complete. Given either of these possibilities, one of the tasks that seems to be accomplished during sentence wrap-up is to "handle any inconsistencies that could not be resolved within the sentence" (Just \& Carpenter, 1980, p. 345).

In addition to the influence of such factors as elaboration and distance on the speed with which backgrounded information is reinstated, it is possible that the coherence of the text also influences the time course, with the integration process proceeding more slowly for elaborative inferences than for inferences that are necessary for coherence, such as connecting an anaphor with its referent. Assuming a capacity-constrained working memory system (e.g., Goldman \& Varma, 1995), or limited attentional resources, precedence may be given to processes involved in building a locally coherent representation. To the extent that readers' attentional resources are consumed with local, sentence-level processing, there may not be sufficient resources left for more global processes, such as integrating the current sentence with information from earlier in the passage. As a result, these processes either may not be completed or may be delayed.

In support of this idea, when there was an inconsistency with regard to a character's goal (Huitema, Dopkins, Klin, \& Myers, 1993), the role of sentence boundaries seemed to have been less critical than in the present experiments. That is, even though well over $50 \%$ of the target lines (e.g., Then he put on a sweatshirt) did not end with a period, there was an immediate slowdown when they were inconsistent with an earlier stated goal (e.g., George knew he had to cool off or he'd get heat stroke). One possible reason for the slowdown on the target line in the absence of a sentence boundary is that goal information is more salient, or more critical to the discourse representation, than are the character traits that were contradicted in the present experiments. It should be noted, of course, that these comparisons are merely speculative; there are a number of confounding variables between the two sets of studies, such as the amount of backgrounding.

Finally, the results of the present experiments suggest that syntactic boundaries, such as the period at the end of the sentence, may play an important role in the comprehension process. Although the results of Experiment 3 demonstrated that the processes occurring during sentence wrap-up are not initiated by the period, the integration of information needed for global coherence was clearly facilitated by the sentence boundary. The present results clearly indicate that more attention should be paid to the influence of linguistic variables, such as syntactic boundaries, in models of discourse comprehension.

\section{REFERENCES}

Albrecht, J. E., \& Myers, J. L. (1998). Accessing distant text information during reading: Effects of contextual cues. Discourse Processes, 26, 87-107.

Albrecht, J. E., \& O'Brien, E. J. (1993). Updating a mental model: Maintaining both local and global coherence. Journal of Experimental Psychology: Learning, Memory, \& Cognition, 19, 1061-1070.

Cook, A. E., Halleran, J. G., \& O'Brien, E. J. (1998). What's readily available? A memory-based view of text processing. Discourse Processes, 26, 109-129.

Dell, G. S., MCKoon, G., \& RatClifF, R. (1983). The activation of antecedent information during the processing of anaphoric reference in reading. Journal of Verbal Learning \& Verbal Behavior, 22, 121-132.

DUFFY, S. A., \& RAYNER, K. (1990). Eye movements and anaphor resolution: Effects of antecedent typicality and distance. Language \& Speech, 33, 103-119.

Garnham, A., Oakhill, J., \& Cain, K. (1997). The interpretation of anaphoric noun phrases: Time course, and effects of overspecificity. Quarterly Journal of Experimental Psychology, 50A, 149-162.

Goldman, S. R., \& Varma, S. (1995). CAPing the constructionintegration model of discourse comprehension. In C. A. Weaver \& S. Mannes (Eds.), Discourse comprehension: Essays in honor of Walter Kintsch (pp. 337-358). Hillsdale, NJ: Erlbaum.

GUZMÁN, A. E. (1998). The role of focus and syntactic boundaries in narratives. Unpublished master's thesis, State University of New York at Binghamton.

Huitema, J. S., Dopkins, S., Klin, C. M., \& Myers, J. L. (1993). Connecting goals and actions during reading. Journal of Experimental Psychology: Learning, Memory, \& Cognition, 19, 1053-1060.

JUST, M. A., \& CARPENTER, P. A. (1977). Cognitive processes in comprehension. Hillsdale, NJ: Erlbaum.

JUST, M. A., \& CARPENTER, P. A. (1980). A theory of reading: From eye fixations to comprehension. Psychological Review, 87, 329-354.

KINTSCH, W. (1988). The role of knowledge in discourse comprehension: A construction-integration model. Psychological Review, 95, 163-182.

KLIN, C. M. (1995). Causal inferences in reading: From immediate activation to long-term memory. Journal of Experimental Psychology: Learning, Memory, \& Cognition, 21, 1483-1494.

KLIN, C. M., \& MyERS, J. L. (1993). Reinstatement of causal information during reading. Journal of Experimental Psychology: Learning, Memory, \& Cognition, 19, 554-560.

McDonald, J. L., \& MacWhinney, B. (1995). The time course of anaphor resolution: Effects of implicit verb causality and gender. Journal of Memory \& Language, 34, 543-566.

McKoon, G., Gerrig, R. J., \& Greene, S. B. (1996). Pronoun resolution without pronouns: Some consequences of memory-based text processing. Journal of Experimental Psychology: Learning, Memory, \& Cognition, 22, 919-932.

Myers, J. L., \& O'Brien, E. J. (1998). Accessing the discourse representation during reading. Discourse Processes, 26, 131-157. 
Myers, J. L., O'Brien, E. J., Albrecht, J. E., \& Mason, R. A. (1994) Maintaining global coherence during reading. Journal of Experimental Psychology: Learning, Memory, \& Cognition, 20, 876-886.

OAKhill, J., Garnham, A., \& Vonk, W. (1989). The on-line construction of discourse models. Language \& Cognitive Processes, 4, 263-286.

O'Brien, E. J., Duffy, S. A., \& Myers, J. L. (1986). Anaphoric inference during reading. Journal of Experimental Psychology: Learning, Memory, \& Cognition, 12; 346-352.

O'Brien, E. J., Raney, G. E., Albrecht, J. E., \& Rayner, K. (1997) Processes involved in the resolution of explicit anaphors. Discourse Processes, 23, 1-24.

O'Brien, E. J., Rizzella, M. L., Albrecht, J. E., \& Halleran, J. G. (1998). Updating a mental model: A memory-based text processing view. Journal of Experimental Psychology: Learning, Memory, \& Cognition, 24, 1200-1210.

Rayner, K., Sereno, S. C., Morris, R. K., Schmauder, A. R., \& Clifton, C. (1989). Eye movement and on-line language comprehension processes. Language \& Cognitive Processes, 4, 21-49.
TUKEY, J. W. (1977). Exploratory data analysis. Reading, MA: AddisonWesley.

\section{NOTES}

1. The full set of materials for all three experiments can be obtained from the authors via e-mail.

2. According to Tukey's (1977) criterion, a score, $X$, is defined as an outlier if $X>H_{\mathrm{U}}+(1.5) \times\left(H_{\mathrm{U}}-H_{\mathrm{L}}\right)$ or $X<H_{\mathrm{L}}+(1.5) \times\left(H_{\mathrm{U}}-H_{\mathrm{L}}\right)$. $H_{\mathrm{U}}$ and $H_{\mathrm{L}}$ refer to the scores that cut off the upper and lower $25 \%$ of the ranked scores, respectively.

3. The mean reading times in Experiment $2 \mathrm{~B}$ are approximately $98 \mathrm{msec}$ longer than those in Experiment $2 \mathrm{~A}$. This cross-experimental comparison is probably due to differences in the subject pool: Whereas Experiment $2 \mathrm{~A}$ was conducted during the academic year, primarily with freshmen from the State University of New York at Binghamton, Experiment $2 \mathrm{~B}$ was conducted during the summer session with a much wider variety of participants.

\section{APPENDIX A \\ Sample Passage for Experiment 1}

\section{Introduction}

Today, Mary was meeting a friend for lunch. She arrived early at the restaurant and decided to get a table. After she sat down, she started looking at the menu.

\section{Critical Elaboration}

Consistent version. This was Mary's favorite restaurant because it had terrific junk food. Mary really liked to splurge sometimes and eat just about anything that wasn't good for her.

Inconsistent version. This was Mary's favorite restaurant because it had fantastic health food. Mary had been a strict vegetarian for ten years and was careful not to eat any fat.

\section{Backgrounding}

Mary kept glancing at her watch impatiently because her friend, Ruth, was 15 minutes late. After another ten minutes, Ruth arrived. It had been a few months since they had seen each other. Because of this they had a lot to talk about and chatted for over a half hour. Finally, Mary signaled the waiter to come take their orders. Mary checked the menu one more time. She had a hard time deciding what to have for lunch. Mary was finally able to make her choice.

\section{Target Line}

She ordered a cheeseburger and fries

\section{Posttarget Line}

and handed the menu over to Ruth.

\section{End of Passage}

Ruth ordered and then continued chatting with Mary.

\section{Comprehension Question}

Was Mary meeting her husband for lunch? 


\section{APPENDIX B \\ Sample Passage for Experiments $2 A$ and 2B}

\section{Introduction}

Today, Mary was meeting a friend for lunch. She arrived early at the restaurant and decided to get a table. After she sat down, she started looking at the menu.

\section{Critical Elaboration}

This was Mary's favorite restaurant because it had fantastic vegetarian food. Mary had been a strict vegetarian for ten years and was careful not to eat any fat.

\section{Backgrounding}

Mary kept glancing at her watch impatiently because her friend, Ruth, was 15 minutes late. After another ten minutes, Ruth arrived. It had been a few months since they had seen each other. Because of this they had a lot to talk about and chatted for over a half hour. Finally, Mary signaled the waiter to come take their orders. Mary checked the menu one more time. She had a hard time deciding what to have for lunch. Mary was finally able to make her choice.

\section{Target Line \\ Recognition Probe \\ VEGETARIAN \\ Comprehension Question \\ Was Mary meeting her husband for lunch?}

Contradiction version. She ordered a cheeseburger and fries $\{\}.\{$ For Experiment $2 \mathrm{~A}\}$

Neutral version. She ordered a large iced cappuccino $\{$.$\} For Experiment 2A\}$

\section{APPENDIX C \\ Sample Passage for Experiment 3}

\section{Introduction}

Today, Mary was meeting a friend for lunch. She arrived early at the restaurant and decided to get a table. After she sat down, she started looking at the menu.

\section{Critical Elaboration}

Consistent version. This was Mary's favorite restaurant because it had terrific junk food. Mary really liked to splurge sometimes and eat just about anything that wasn't good for her.

Inconsistent version. This was Mary's favorite restaurant because it had fantastic health food. Mary had been a strict vegetarian for ten years and was careful not to eat any fat.

\section{Backgrounding}

Mary kept glancing at her watch impatiently because her friend, Ruth, was 15 minutes late. After another ten minutes, Ruth arrived. It had been a few months since they had seen each other. Because of this they had a lot to talk about and chatted for over a half hour. Finally, Mary signaled the waiter to come take their orders. Mary checked the menu one more time. She had a hard time deciding what to have for lunch. Mary was finally able to make her choice.

\section{Target Line}

She ordered a cheeseburger and fries and handed the menu

\section{Posttarget Line}

back to the waiter.

\section{Last Line of Passage}

Ruth ordered and then continued chatting with Mary.

\section{Comprehension Question}

Was Mary meeting her husband for lunch? 